\title{
Expressões policomponenciais em libras: estatuto e processo de ensino e aprendizagem como L2
}

\section{Policomponential expressions in libras: statute and process of teaching and learning as L2}

\section{Expresiones policomponenciales en libras: estatuto y proceso de enseñanza y aprendizaje como L2}

\author{
(iD) Marcelo Porto \\ Universidade Federal do Paraná (UFPR), Curitiba, Paraná, Brasil. \\ E-mail: marcelo.porto@ufpr.br \\ iD Lídia da Silva \\ Universidade Federal do Paraná (UFPR), Curitiba, Paraná, Brasil. \\ E-mail: lidiaufpr@gmail.com
}

\begin{abstract}
Resumo: O presente trabalho tem o objetivo de discutir o estatuto das expressões policomponenciais da Libras e refletir sobre o processo de ensino e aprendizagem dessas expressões pelo aprendiz ouvinte brasileiro. Na primeira parte, apresentam-se as ideias de Frydrych (2019), assumindo com Liddell e Metzger (1998), e McCleary e Viotti (2011), a existência de simbiose entre componentes linguísticos e gestuais para explicar tais construções. Na segunda parte, tomam-se os dados advindos das pesquisas de Silva (2018) e Kurz, Mullaney e Occhino (2019), analisando-os a luz da proposta de Taub et al. (2008) para refletir sobre o processo de ensino e aprendizagem na Libras como segunda língua (L2) para ouvintes. Conclui-se que as expressões policomponenciais são compostas por elementos linguísticos e gestuais, e quanto ao processo de ensino e aprendizagem, conclui-se que ocorrem transferências
\end{abstract}


de alguns dos traços gestuais à língua e, portanto, a prática pedagógica precisa aproveitar o repertório gestual do aprendiz.

Palavras-chaves: Libras. Expressões policomponenciais. Estatuto. Ensino e aprendizagem.

Abstract: This paper aims to discuss the status of Libras polycomponential expressions and reflect on the teaching and learning process of these expressions by the Brazilian listening learner. In the first part, it presents the ideas of Frydrych (2019) and assumes with Liddell and Metzger (1998) and McCleary and Viotti (2011) the existence of symbiosis between linguistic and gestural components to explain such constructions. In the second, part takes the data from the research by Silva (2018) and Kurz, Mullaney and Occhino (2019) and analyzes them in the light of the proposal by Taub et al. (2008) to reflect on the teaching and learning process in Libras as a second language (L2) for listeners. It concludes that polycomponential expressions are composed of linguistic and gestural elements and as for the teaching and learning process, it evaluates that given the transfer of some of the gestural traits, pedagogical practice needs to take advantage of the gestural use to optimize language learning.

Keywords: Libras. Polycomponent expressions. Statute. Teaching and learning.

Resumen: Este artículo tiene como objetivo discutir el estado de las expresiones policomponenciales de Libras y reflexionar sobre el proceso de enseñanza y aprendizaje de estas expresiones por parte del aprendiz brasileño. En la primera parte, presenta las ideas de Frydrych (2019) y asume con Liddell y Metzger (1998) y McCleary y Viotti (2011) la existencia de simbiosis entre componentes lingüísticos y gestuales para explicar tales construcciones. En el segundo, parte toma los datos de la investigación de Silva (2018) y Kurz, Mullaney y Occhino (2019) y los analiza a la luz de la propuesta de Taub et al. (2008) para reflexionar sobre el proceso de enseñanza y aprendizaje en Libras como segunda lengua (L2) para los oyentes. Concluye que las expresiones policomponenciales 
están compuestas por elementos lingüísticos y gestuales y en cuanto al proceso de enseñanza y aprendizaje, evalúa que dada la transferencia de algunos de los rasgos gestuales, la práctica pedagógica necesita aprovechar el uso gestual para optimizar el aprendizaje de la lengua.

Palabras clave: Libras. Expresiones de policomponentes. Estatuto. Enseñando y aprendiendo.

Submetido em 11 de abril de 2020.

Aceito em 15 de junho de 2020.

Publicado em 08 de julho de 2021. 
Expressões policomponenciais em libras: estatuto e processo de ensino e aprendizagem... Marcelo Porto • Lídia da Silva

\section{Introdução}

Em uma rápida procura sobre o significado de "gestualidade" no dicionário online de língua portuguesa, encontra-se a definição: "aquilo que se faz com o gesto" e, em Correa (2007), como sendo uma área interdisciplinar, cujos estudos iniciaram na antiguidade. Voltando à origem latina do termo "gesto", sabe-se que o significado de gesture é "movimento do corpo, mãos, braço, cabeça". Gesto, segundo Kendon (2004), também é um ato intencional usado para fins de comunicação.

Essa caracterização - de gesto - é facilmente identificável em comunicação em língua oral, em contexto de interação face a face. Normalmente, o falante realiza "movimento com o corpo, mãos, braço e cabeça" enquanto emite enunciados verbais, o que ocorre devido ao fato de o corpo ser comunicativo (MCNEILL, 2000).

Esses gestos que ocorrem simultaneamente com a fala, são produzidos espontaneamente pelos falantes e apresentam grande variação de realização. McNeill (2000), ao observá-los, categorizou-os entre gestos beat (como bater palma e estalar os dedos), gestos emblemáticos (como mostrar o polegar com sentido de positivo) e gestos de apontamento. Silva (2014, p. 26) diz que há ainda os gestos icônicos que são aqueles "usados para apresentar algum aspecto sensorialmente perceptível" dos objetos da realidade. Todos esses gestos "desempenham uma parte na comunicação e provêm informações para os co-participantes sobre conteúdos semânticos dos enunciados" (CORREA, 2007, p. 30).

Gestualidade, então, além de ser compreendida como área interdisciplinar e como o conjunto de gesto (neste texto usado como sinônimo de gesticulação e ação gestual), também se caracteriza por ser universal e manifestar-se sincronamente em todas as línguas naturais. Nas palavras de Carneiro (2016, p. 122): 
Expressões policomponenciais em libras: estatuto e processo de ensino e aprendizagem... Marcelo Porto • Lídia da Silva

Os gestos não podem ser vistos a partir de uma ação física, mas de uma noção semiótica, já que expressam o lado imagético do pensamento durante o discurso. Gestos são gradientes, não categóricos, fazem parte da linguagem humana e do processo de produção das línguas naturais. São abundantes e onipresentes através das culturas e das línguas. Assim, a ação gestual pode ser considerada um universal linguístico.

A discussão a respeito do estatuto dessa manifestação gestual, todavia, é que não parece ser consensual e apresenta desdobramentos na área interessada nos processos de ensino e aprendizagem de Libras. Diz-se isso porque caso a gestualidade seja interpretada como base para constituição dos signos linguísticos, tal como aponta Frydrych (2019), então as expressões policomponenciais serão assim consideradas, logo, sua aprendizagem não se distinguirá da aprendizagem de nenhum outro sinal. Se, no entanto, assumir-se, como Liddell (2003) e outros, que língua e gesto são duas facetas pertencentes a um único sistema cognitivo e que ambos materializam-se durante a sinalização, as expressões policomponenciais serão consideradas uma composição entre gesto e língua, logo, à área interessada nos processos de ensino e aprendizagem cabe conceber práticas pedagógicas eficientes.

Parece, então, que se está diante de duas constatações distintas e, por isso, é necessário trazer resposta a algumas questões de pesquisa:

I. Qual é o estatuto das expressões policomponenciais (signos linguísticos ou uma combinação entre língua e gesto)?

II. O que podemos considerar a respeito do processo de ensino e aprendizagem das expressões policomponencias da Libras ao aprendiz de L2?

Discutir e refletir sobre essas questões é o objetivo deste texto de caráter bibliográfico. Quanto às partes que compõem o estudo, na primeira seção, apresentamos, brevemente, o embasamento 
Expressões policomponenciais em libras: estatuto e processo de ensino e aprendizagem... Marcelo Porto • Lídia da Silva

teórico relativo ao estatuto das expressões policomponenciais, dando destaque ao espaço token. Na segunda seção, são apresentados exemplos de produção de ouvintes de modo que possamos refletir o que tais dados dizem a respeito do processo de aprendizagem das expressões policomponenciais. Na última seção, apresentamos nossas conclusões.

\section{O estatuto das expressões policomponenciais da libras}

Na ausência da língua de sinais, sabe-se que os gestos são de valor inestimável às pessoas surdas, pois quando estão diante de uma comunicação em língua oral (e, por isso, não podem entender o que é dito) elas se valem do "movimento do corpo, mãos, braço e cabeça" da pessoa para compreender a mensagem. Isso ocorre inclusive nas famílias em que há pais ouvintes - que não sabem a Libras -, a comunicação se dá por meio de "sinais caseiros", os quais são gesticulações combinadas (PORTO, 2016). Mas, e quando há produção em língua de sinais, como se identificam os gestos, uma vez que os canais de produção e recepção são os mesmos?

Para começar a pensar a esse respeito, destaca-se que, em toda produção sinalizada, percebe-se aquelas realizações descritas para gesture e inúmeras outras expressões faciais e variadas direções de olhar (BARBOSA, 2014). Ocorre que tais realizações são comumente descritas pela linguística tradicional como pronomes, morfemas, realizações sintáticas e outras. Ou seja, há uma grande tentativa, por parte dessa ciência, de inserir os elementos gestuais na categoria linguística.

Liddell (2003) explica que Stokoe', na tentativa de defender a língua americana de sinais (ASL) como uma língua natural, abriu mão de explanar sobre sua gestualidade, limitando-se a argumentar sobre sua estrutura (que era composta de elementos discretos e sistematizáveis como qualquer língua oral). Depois de Stokoe,

1 William C. STokoe Jr (1919-2000) foi um estudioso que pesquisou extensivamente a ASL enquanto trabalhava na Gallaudet Universidade. Ele cunhou os três principais parâmetros fonológicos da língua de sinais. 
Expressões policomponenciais em libras: estatuto e processo de ensino e aprendizagem... Marcelo Porto • Lídia da Silva

muitos linguistas (principalmente de orientação gerativa) reuniram esforços para mostrar que a língua de sinais era composta pelos mesmos tipos de elementos e funcionava de acordo com um conjunto semelhante de regras e restrições que as línguas orais, o que levou à rejeição de qualquer expressão gestual na estrutura formal da língua (FUKS; TOBIN, 2009).

Entretanto, o estatuto da gestualidade, nos estudos das línguas de sinais, tem ganhado força recentemente, inclusive com ascensão de diferentes perspectivas teóricas sobre o fenômeno.

Frydrych (2019), sob as bases da linguística saussureana, concebe que as línguas de sinais são "tradução do pensamento", manifestações significantes simbólicas e constata que

as línguas de sinais são línguas, portanto, por serem conjuntos, sistemas de valores linguísticos evidenciados na forma de signos linguísticos (os quais, por sua vez, são formados por unidades materiais e mentais), baseados completamente nas relações desses valores-signos no âmbito do sistema que compõe e, ao mesmo tempo, estão contidos (FRYDRYCH, 2019, p. 3).

A esse conceito de língua, a autora adiciona a compreensão de que a materialidade das línguas de sinais é intrínseca à gestualidade, que pode ser compreendida a partir do princípio saussuriano da dupla essência da linguagem. Frydrych (2019) apresenta a ilustração abaixo para explicar sua proposição. 
Expressões policomponenciais em libras: estatuto e processo de ensino e aprendizagem... Marcelo Porto • Lídia da Silva

Figura 1 - Dualidade do fenômeno gestual

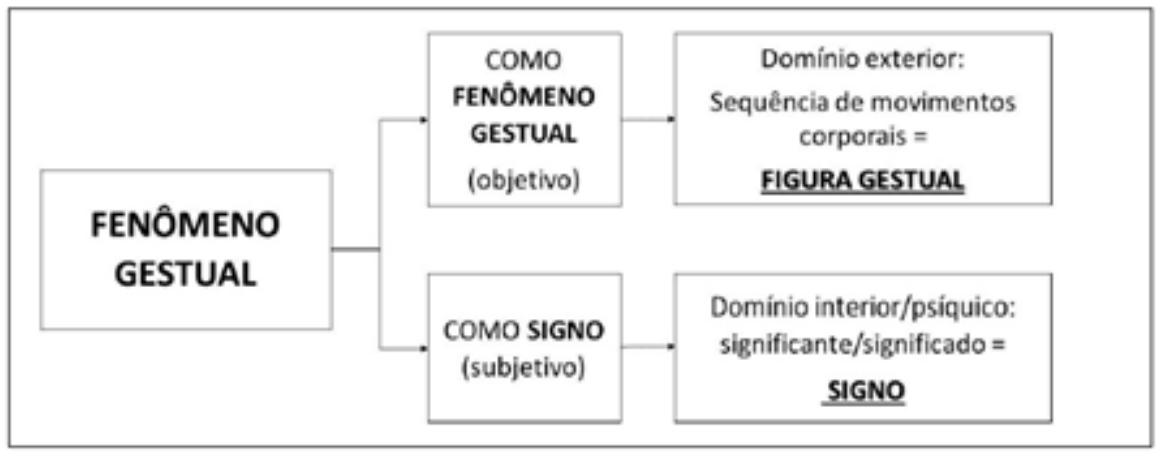

Fonte: Frydrych (2019, p. 9).

Por uma questão de limitação de espaço, não se aprofundará neste texto a tese da autora, mas é importante demarcar que sua constatação é de que a gestualidade pode ser tomada tanto como puro gesto (como um corpo-em-ação) quanto como signo linguístico (com caráter representacional).

Da parte da linguística cognitiva, o entendimento é outro. Argumenta-se que os elementos considerados propriamente linguísticos (discretos e segmentáveis) são, frequentemente, combinados com elementos gestuais (gradientes e analógicos) para a construção do discurso. Pondera-se também que ambas as formas de expressões (gestuais e linguísticas) são produzidas visualmente e contribuem para a construção de significado (BARBOSA, 2014). Advoga-se ainda que os gestos são responsáveis pela organização das línguas de sinais desde o nível lexical até sua gramática e o seu discurso² (MCCLEARY; VIOTTI, 2011).

\footnotetext{
2 No léxico, a gestualidade é vista como parte do processo de evolução da língua de sinais, por exemplo. Wilcox (2005) por meio de dados históricos das línguas de sinais americana, catalã, francesa e italiana, ocupou-se em esclarecer que os gestos entraram no sistema linguístico por meio da gramaticalização e Fuks e Tobin (2009) apontam que os gestos influenciam a estrutura dos sinais da língua de sinais israelense. McCleary e Viotti (2011) demonstram que há sinais - como os verbos policomponenciais - que são realizados de forma diferente a depender das características do referente, e que essa variação e iconicidade se justificam, exatamente, por serem formados por mais de um componente de significação (a gestualidade). Na gramática, Duncan (2005) demonstra que a realização de gestos gradiente são coproduzidos com representações categóricas, assinalando que a gestualidade realiza-se de forma padronizada junto a sinais da língua de sinais taiwanesa. No Brasil, Leite (2008), tratando de recursos atencionais presentes na interação face a face, aponta para a gestualidade como uma pista de segmentação. Por fim, Silva e Strazzi (2017) observam que no discurso em Libras há presença de gestos de acompanhamento, de intervalo e consequência. e que, na comparação entre os dados das narrativas produzidas por surdos e ouvintes, constatam que tais gestos são mais frequentes na sinalização dos primeiros já que esses últimos, preferencialmente, fazem uso de itens lexicais convencionalizados para expressarem suas ideias.
} 
Expressões policomponenciais em libras: estatuto e processo de ensino e aprendizagem... Marcelo Porto • Lídia da Silva

A explicação dessa simbiose entre língua e gesto ancora-se em Liddell e Metzger (1998), os quais, buscando preceitos da teoria da integração conceitual, apontam os mapeamentos cognitivos que são envolvidos durante a interação. Como tais apontamentos encontram adesão a este estudo, eles são ilustrados pela imagem abaixo:

Figura 2 - Espaço real, espaço do evento e espaço mental integrado

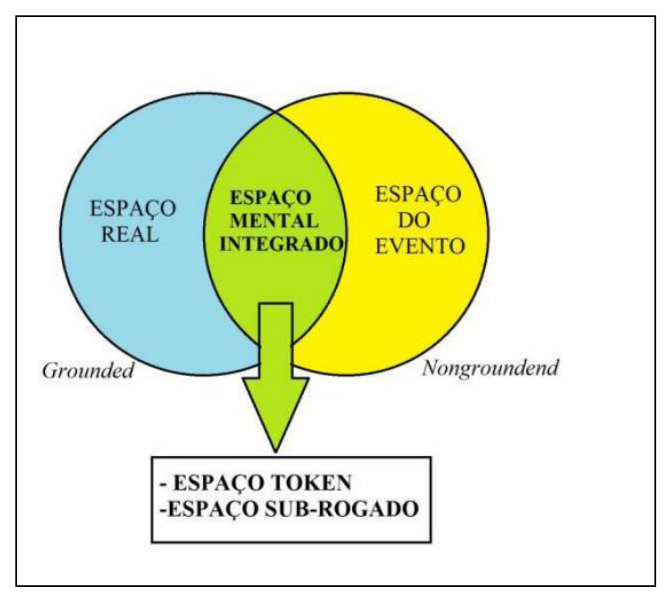

Fonte: Anchieta (2017, p. 64)

Segundo Anchieta (2017, p. 64), essa imagem é "um esquema de função restritamente ilustrativa, não apresentando qualquer estatuto teórico", mas pensamos que por meio dela podemos compreender que, na interação, os corpos físicos dos participantes compõem o contexto discursivo e trazem significado à comunicação. Silva $(2014$, p. 7) diz que esses corpos corroboram as camadas de significação que são construídas conjuntamente durante as interações, tratando-se, portanto, de "espaços intersubjetivos". Os corpos físicos, que estão em interação face a face, compartilham de um espaço real físico (apresentado em azul na imagem) que é "baseado em estímulos sensoriais que recebemos do ambiente e que são combinados com o conhecimento de mundo (SILVA, 2014, p. 9)".

Além desse espaço físico, há o espaço mental (ou espaço do evento, apresentado em amarelo na imagem) que são "ferramen- 
Expressões policomponenciais em libras: estatuto e processo de ensino e aprendizagem... Marcelo Porto • Lídia da Silva

tas cognitivas através das quais pensamos, agimos e organizamos o nosso discurso" (BARBOSA, 2014).

O destaque apresentado em verde na imagem - espaço mental integrado - é a conceitualização intersubjetiva compartilhada entre os falantes. Durante a produção de uma narrativa, por exemplo, conceitos mentais (sobre localização) são atribuídos às entidades que têm uma localização no espaço físico real. Para tanto, o sinalizante lança mão de vários recursos expressos nos chamados espaço token e espaço sub-rogado ${ }^{3}$. A próxima subseção dedica-se a breve apresentação do primeiro espaço.

\title{
O espaço token ${ }^{4}$ as expressões policomponenciais
}

Para tratar sobre o espaço token, Liddell (2003) apresenta o exemplo de um sinalizante realizando uma exposição teórica sobre questões relativas às pessoas surdas e ouvintes. Abaixo a figura apresentada pelo autor:

Figura 3 - Ilustração do espaço token

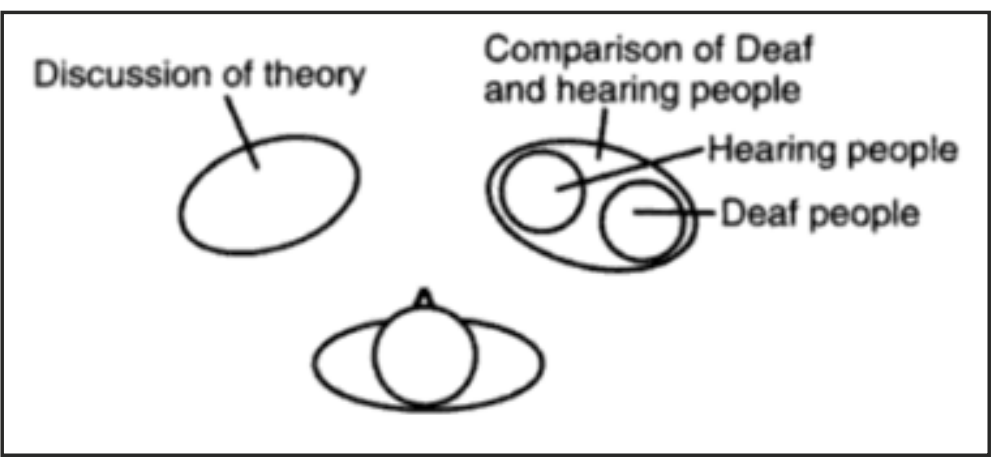

Fonte: Liddell (2003, p. 212)

\begin{abstract}
3 Espaço sub-rogado, também chamado de referenciação com o corpo, ação construída, processo anafórico, troca de papéis, incorporação, discurso em primeira pessoa, perspectiva do personagem, pantomimas, gesto imagético, fala construída, promulgação, mudança referencial e transferência pessoal, segundo McCleary e Viotti (2011, p. 298), é essencial para a sinalização. Os autores explicam que "o corpo do sinalizador, ou uma parte dele, se torna, então, um subrogado de alguém ou de alguma coisa do espaço do evento". Dizem ainda que o sinalizador pode usar expressões faciais e gestos e pode fazer demonstrações mímicas para representar um determinado evento. Moreira (2007, p. 51) também comenta que essas "expressões faciais", "gestos", e "mímicas" são usadas de forma rápida, organizada e sutil. McCleary e Viotti (2011), assim como Moreira (2007), adotam o conceito de espaço sub-rogado que advém de Liddell (1995). Trata-se, então, de o enunciador dispor de todo o seu corpo (movimento de tronco, ombro, braço, olhar, expressão facial) para representar as ações desempenhadas pela entidade. 4 Devido ao crescente interesse por essa construção por parte da linguística das línguas de sinais, tem havido grande proliferação de terminologias, já que pesquisadores de diferentes campos teóricos a tem estudado, dentre as quais se destacam espaço de sinalização, espaço articulatório, espaço semântico, espaço gramatical, espaço narrativo e R-locus.
\end{abstract}


Expressões policomponenciais em libras: estatuto e processo de ensino e aprendizagem... Marcelo Porto • Lídia da Silva

Liddell (2003, p. 212) explica que "o sinalizante associou os surdos e os ouvintes em duas distintas posições no espaço à frente do corpo [...] e, portanto, estabeleceu dois espaços conceituais." Quando realizava as comparações entre essas pessoas, o sinalizante girava seu torso para direita ou para esquerda, apontava e sinalizava nessa direção. Fazia isso, pois se tratava de referentes diferentes do mesmo espaço mental. As peças se juntam, diz o autor, para uma conceitualização ainda mais complexa quando o sinalizante refere-se à língua e à cultura de cada uma das comunidades referidas e, nesta parte, "a rotação do corpo é mais neutra".

Percebe-se então que o espaço token é o espaço à frente do corpo que é usado "para se referir às pessoas que não estão presentes no momento da enunciação ou para se referir a assuntos em geral" (MOREIRA, 2007, p. 40). Neste espaço token é que se descrevem concepções em língua de sinais, as quais são expressas - entre outras formas - por meio da configuração de mão (CM), da localização e do movimento do sinal. Essas expressões codificam a presença e o movimento de entidades, e a forma e extensão de superfícies (LIDDELL, 2003). Para clarear essa afirmação, apresentamos a figura abaixo: 
Expressões policomponenciais em libras: estatuto e processo de ensino e aprendizagem... Marcelo Porto • Lídia da Silva

Figura 4 - Codificação da presença e movimento de entidade e de forma e extensão de superfícies em língua de sinais

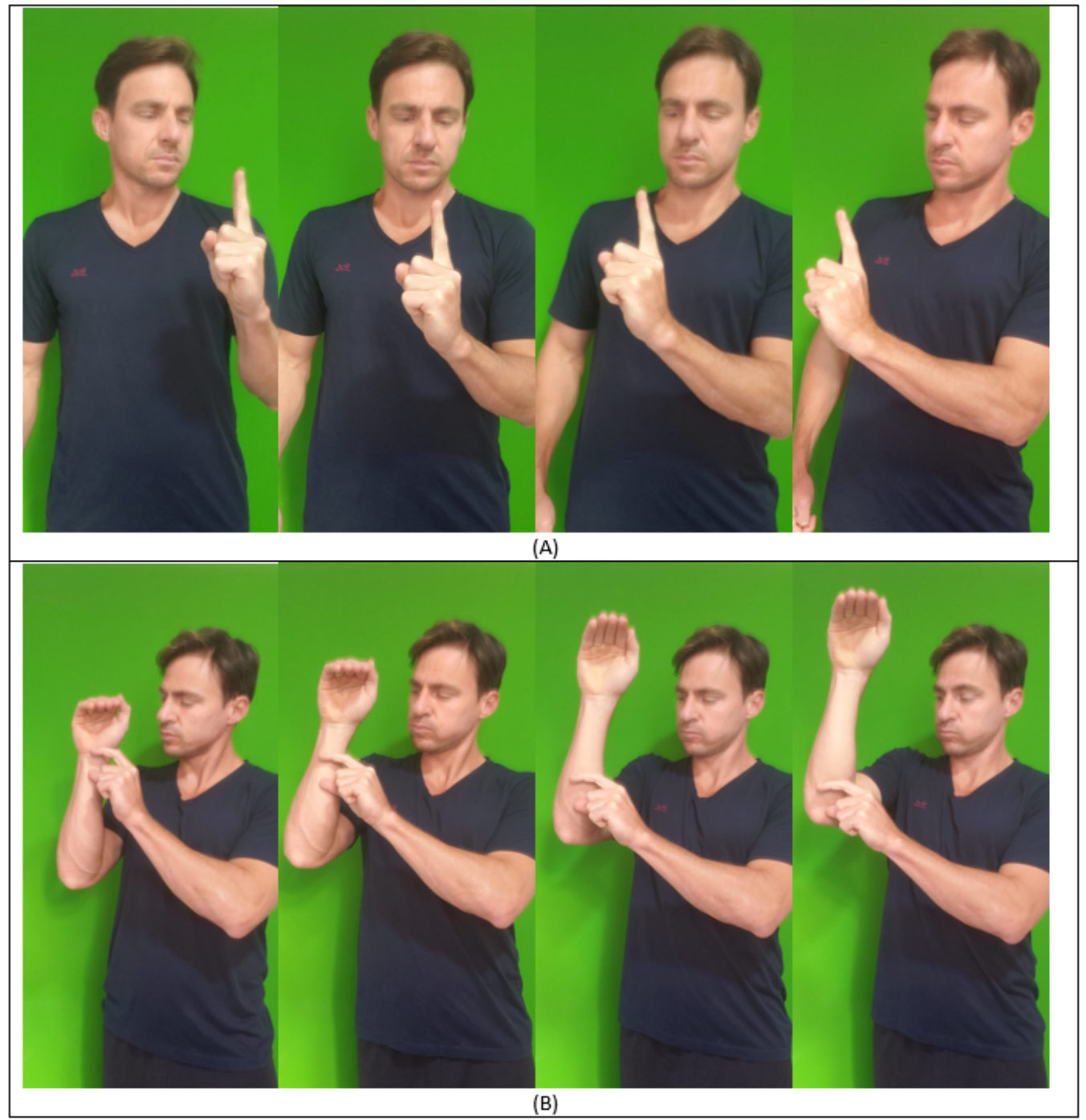

Fonte: Arquivo pessoal dos autores (2020).

Em um contexto discursivo, a imagem (A) pode ser interpretada como menção à presença de uma entidade (uma pessoa) e demonstração do seu movimento (andar), e a imagem (B) como forma e extensão de uma onda do mar (bem como a relação de tamanho com uma pessoa abaixo dela).

Para Liddell (2003), essas realizações são possíveis dada à analogia que o sinalizante faz entre o que vivenciou e o processo conceitual que é descrito. Nessa analogia, explica o autor, o sinalizan- 
Expressões policomponenciais em libras: estatuto e processo de ensino e aprendizagem... Marcelo Porto • Lídia da Silva

te faz uso do movimento, da localização, da direcionalidade e de orientações que são aspectos gradientes, variáveis e transparentes, e da CM. Essa última pode ser compreendida como unidade linguística. Tratam-se, portanto, de expressões policomponenciais ${ }^{5}$ que apresentam - além de aspectos linguísticos - as características de serem gestuais, idiossincráticas, analógicas e icônicas (MCCLEARY, VIOTTI, 2011).

Distinguir tais aspectos é uma questão passível de discussão e pensa-se que o Continuum de Kendon pode ser a base da reflexão.

Figura 5 - Continuum de Kendon ${ }^{6}$

Most Linguistic

Least Linguistic Sign Language $\rightarrow$ Emblems $\rightarrow$ Pointing $\rightarrow$ Pantomimes $\rightarrow$ Gesticulation

Fonte: Fuks e Tobin (2009, p. 1).

O Continuum indica que formas gestuais mais à esquerda têm características linguísticas, por serem mais convencionalizadas. Por outro lado, formas gestuais mais à direita se distanciam dessas características por serem mais idiossincráticas. Essa é uma interpretação semiótica que nos permite compreender como é possível produzir um gesto e um elemento linguístico ao mesmo tempo em língua de sinais?

Gestos, de acordo com McNeill (2000) e Carneiro (2016), expressam o lado imagético do pensamento durante a expressão da fala (sinalizada, inclusive). Ou seja, o aparecimento de gestos, no momento da fala sinalizada, se dá em decorrência do trabalho de

\footnotetext{
5 Esse tipo de produção é comumente chamada - pelos sinalizantes surdos e ouvintes - como "classificadores" (ou construções classificadoras), quando, em contexto de ação, são tratados ainda como verbos descritivos (CARNEIRO, 2016).

6 A gesticulação refere-se a movimentos espontâneos e idiossincráticos do corpo que aparecem no processo de fala que podem ser gramaticalmente mesclados na estrutura da frase (por exemplo, movimentos que podem completar uma frase substituindo uma de suas partes). As pantomimas são representações icônicas e idiossincráticas de ações cotidianas e não aparecem necessariamente com a fala [...]. McNeill (2000) coloca a apontação entre pantomimas e emblemas porque apontar tem uma forma convencional em todas as culturas. Apontar também é colocado no meio do Continuum porque, em contextos discursivos específicos, seu aparecimento é simultâneo com a forma falada, enquanto, em outros contextos, ele pode ser entendido sem fala. Emblemas, em contraste com pantomimas, expressam uma conexão fixa e estável entre a forma e significado. Seu significado é convencional e, geralmente, aparece na ausência de fala. Emblemas não se combinam para formar frases.

7 McCleary e Viotti (2011, p 291), baseando-se em Duncan (2003), explicam que os gestos nas línguas de sinais, além de ocorrerem simultaneamente com o discurso sinalizado, também aparecem de forma intercalada. Por meio dos uso de outros articuladores que não estejam atuando na codificação dos sinais manuais, ou pela mão que não está ativa na articulação, é possível promover interrupção do fluxo dos sinais.
} 
Expressões policomponenciais em libras: estatuto e processo de ensino e aprendizagem... Marcelo Porto • Lídia da Silva

dois tipos de cognição durante o uso da linguagem: (I) pensamento imagístico global, que se reflete em gestos, e (II) pensamento segmentar linear, que se reflete na língua (FUKS; TOBIN, 2009).

A manifestação de produções distintas pode ser posta no Continuum a depender do tipo de cognição mais ativa. Quer dizer, se a cognição mais ativa for a do pensamento imagístico global acontecerão realizações mais à direita, pois serão mais gestuais. Enquanto que se a realização for mais próxima ao que se convencionalizou em Libras como elemento linguístico, ela estará mais à esquerda do Continuum e vai se referir à cognição do tipo segmentar linear.

Tendo essa perspectiva em vista, voltando-se às imagens (A) e (B), da Figura 4, pode-se compreender porque estas não são formas fixas ou invariáveis de realização da codificação de entidade e superfície referidas acima. Eventualmente, aparecerão gestos simultaneamente aos elementos linguísticos e sua identificação poderá seguir o seguinte critério: o que está convencionalizado como estrutura básica do item lexical será dado como linguístico e todas as ocorrências de mudanças entendidas no contexto, que remetem à produção de imagens, serão codificadas como gestos.

Para elucidar ainda mais essa proposição, são fornecidos os exemplos a seguir: 
Expressões policomponenciais em libras: estatuto e processo de ensino e aprendizagem... Marcelo Porto • Lídia da Silva

Figura 6 - Amostra de codificação em Libras com a presença de componentes linguísticos e gestuais

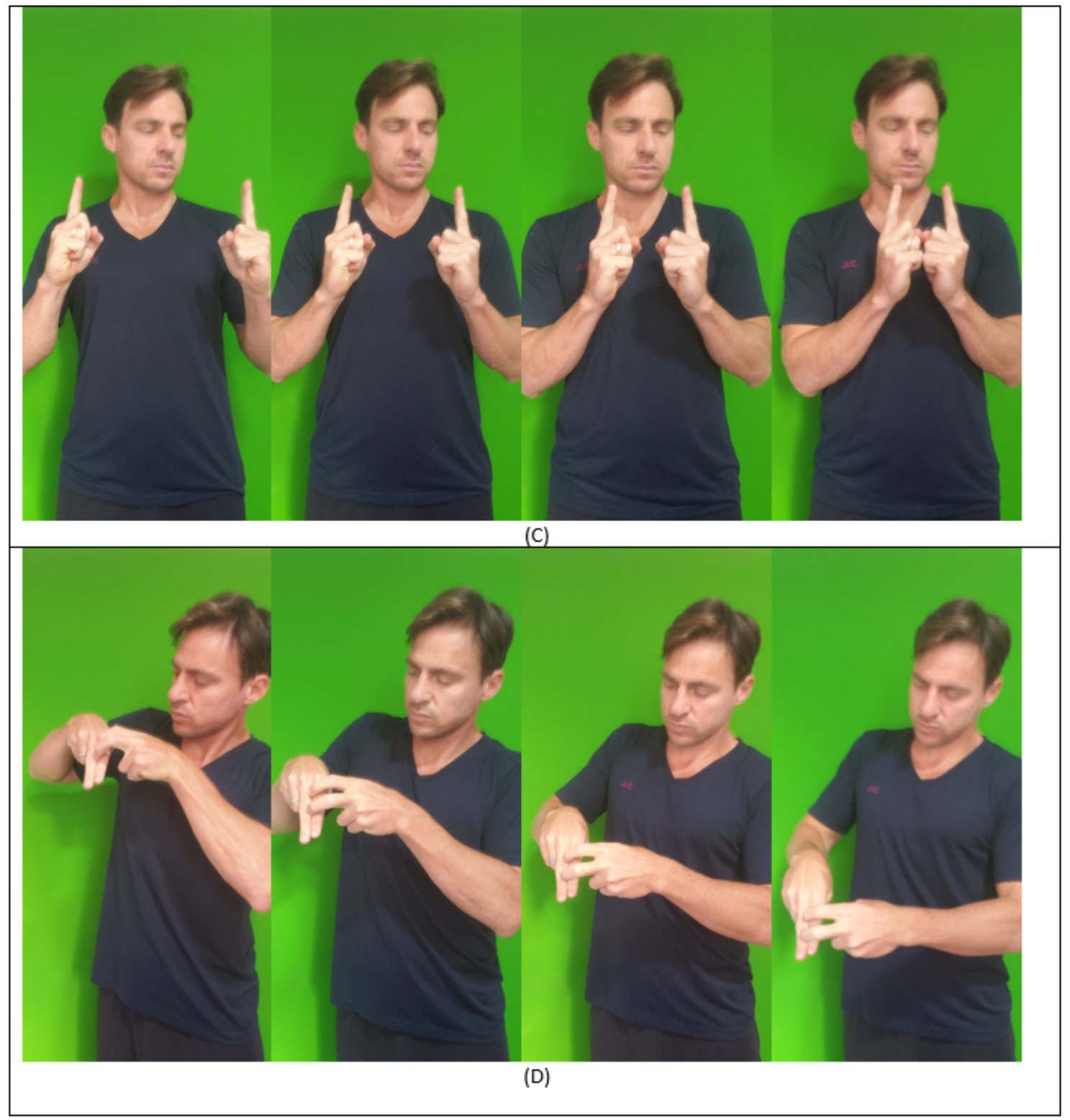

Fonte: Arquivo pessoal dos autores (2020).

Note-se que a imagem (C) está fazendo menção à presença e movimento de entidade com a mesma CM da imagem (A), anteriormente apresentada, só que agora a demonstração do movimento bimanual parece se referir a duas pessoas. A imagem (D), diferentemente do exemplo dado em (B), que codificava a super- 
Expressões policomponenciais em libras: estatuto e processo de ensino e aprendizagem... Marcelo Porto • Lídia da Silva

fície onda, parece estar codificando uma superfície plana sobre a qual se identifica a presença de uma entidade.

Destes sinais, entende-se, com base em Liddell (2003) e no Continuum de Kendon, que a CM de (C) é um elemento linguístico e o movimento e a localização são gestos, uma vez que só são entendidos no contexto de sinalização. Em (D), a estrutura básica seria a entidade codificada por uma CM que lembra as pernas de uma pessoa e a expressão gestual seria a que está remetendo à superfície plana onde a pessoa, conceitualmente, está colocada (os dois dedos da mão direita). Além dessas pode haver inúmeras possibilidades diferentes, que são não convencionalizadas, para codificar tais entidades e superfícies.

Sumarizando as ideias apresentadas nesta seção e trazendo resposta explícita à primeira pergunta de pesquisa, pode-se afirmar que as expressões policomponenciais são estruturas formadas por meio da junção de componentes linguísticos e gestuais, sendo que ambos são produções visuais que corroboram o significado. Além disso destacamos que:

a. os componentes gestuais e linguísticos, para a produção de expressões policomponenciais, são extremamente variáveis, pois refletem o trabalho de duas cognições de um mesmo sistema, bem como a experiência do sinalizante;

b. a CM destas expressões policomponenciais é o elemento considerado discreto e segmentável;

c. O movimento, a localização e a direção são elementos considerados gradientes e analógicos.

Isto posto, na próxima seção passamos à reflexão sobre o processo de ensino e aprendizagem dessas expressões pelo aprendiz de Libras como L2. 
Expressões policomponenciais em libras: estatuto e processo de ensino e aprendizagem... Marcelo Porto • Lídia da Silva

\section{A aprendizagem das expressões policomponenciais por ouvintes sinalizantes de libras como L2}

Inicialmente convém esclarecer a razão de termos escolhido as expressões policomponenciais para discussão e não outras que também se caracterizam por serem compostas de elementos linguísticos e gestuais. Tal escolha foi motivada pelo recorrente discurso (inclusive teórico) de que os chamados classificadores (sinônimo de expressões policomponenciais, no caso) são de difícil reprodução para aprendizes de L2. Em Boers-Visker e Van-Den-Bogaerde (2019), por exemplo, observa-se o resultado de um estudo de caso no qual os autores constatam que os ouvintes não produzem classificadores nas primeiras etapas da aprendizagem e que, ao surgirem (após uns 18 meses de estudos), as produções são restritas e prototípicas à referenciação de pessoas (tal qual o exemplo da imagem (A) da Figura 4). Afirmam ainda que, após quatro anos de instrução, os aprendizes apresentam dificuldade na seleção fonológica do classificador. Haja vista essa motivação, passamos à apresentação das ideias de Taub et al. (2008).

A partir de um estudo longitudinal, envolvendo 18 aprendizes ouvintes, em uma coleta de dados, antes do início do curso de ASL e outra após 8 meses de aulas, Taub et al. (2008) concluem que alguns traços constituidores de expressões policomponenciais são adquiridos logo no início da aquisição porque há transferência da gestualidade.

A transferência a qual os autores se referem são dos gestos que ocorrem com a fala (gesticulação), que acompanham a língua oral e constituem a produção multimodal. Para melhor compreensão, considere-se a figura abaixo. 
Expressões policomponenciais em libras: estatuto e processo de ensino e aprendizagem... Marcelo Porto • Lídia da Silva

\section{Figura 7 - Exemplo de estímulo à produção}

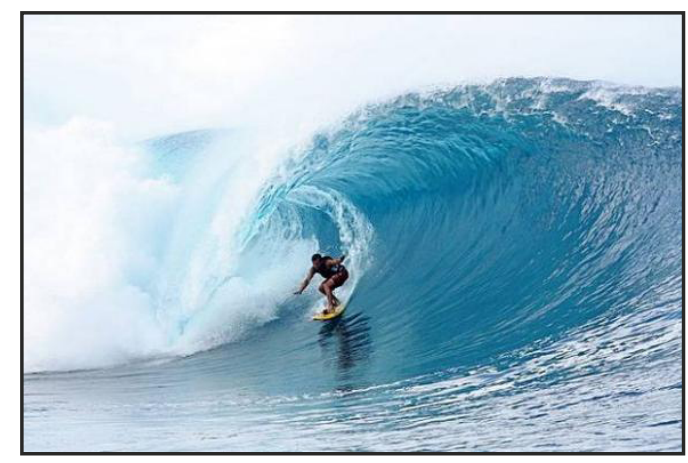

Fonte: Super Interessante (2011).

Se um aprendiz ouvinte tiver que, a seu modo, - descrever a imagem da Figura 7 - ele precisará fazer uso da gestualidade.

Baseando-se em Taub et al. (2008) e inferindo o mesmo resultado para realidade brasileira, pode-se afirmar que, caso a descrição seja feita em português oral, fatalmente, gestos aparecerão durante a fala. Tais gestos serão muito icônicos e, provavelmente, vão preservar a localização do corpo do referente em relação à onda, bem como o seu movimento. Entretanto, haverá formatos de mãos mais ou menos parecidos com as CM da Libras.

Quando esse mesmo aprendiz realizar a descrição em Libras, aquela mesma gestualidade (iconicidade, localização e movimento) vai também estar presente, entretanto a CM - que, segundo Liddell (2003), é o elemento linguístico das expressões policomponenciais - estará comprometida naqueles que a realizaram de forma menos complexa durante a descrição em sua L1.

Essas nuances da gestualidade, que são transferidas à língua, são explicadas pelos autores:

[...] há transferência de tal característica da gesticulação para a ASL, com a evolução dos gestos icônicos não-linguísticos para formas com nuances linguísticas (por exemplo, a configuração de mão correta na ASL). Tal observação sugere que o uso de

8 Disponível em: https://super.abril.com.br/mundo-estranho/quais-sao-as-ondas-mais-temidas-pelos-surfistas/ Acesso em: 02 dez. 2020. 
Expressões policomponenciais em libras: estatuto e processo de ensino e aprendizagem... Marcelo Porto • Lídia da Silva

estruturas semelhantes às classificadoras nos gestos que acompanham a fala poderia constituir um prenúncio de uma aprendizagem precoce das estruturas do discurso em terceira pessoa na ASL (TAUB et al. 2008, p. 282).

Com essa explicação de Taub et al. (2008), tomemos os dados de ouvintes sinalizantes de Libras e ASL apresentados nos estudos de Silva (2018) e Kurz, Mullaney e Occhino (2019), respectivamente, que analisaram produções de verbos policomponenciais para, a partir deles, refletir sobre nossa segunda questão de pesquisa.

Silva (2018) realizou um estudo transversal no qual 7 alunos ouvintes sinalizantes de Libras como L2, matriculados no nível avançado, em seção individual, assistiram à história da pera em um computador e, depois, a recontaram em Libras. A autora tomou a realização abaixo como exemplo prototípico de verbo policomponencial referente a ANDAR-DE- BICICLETA já que era semeIhante às amostras encontradas em sinalização de surdos:

Figura 8 - Verbo policomponencial em Libras ANDAR-DE-BICICLETA

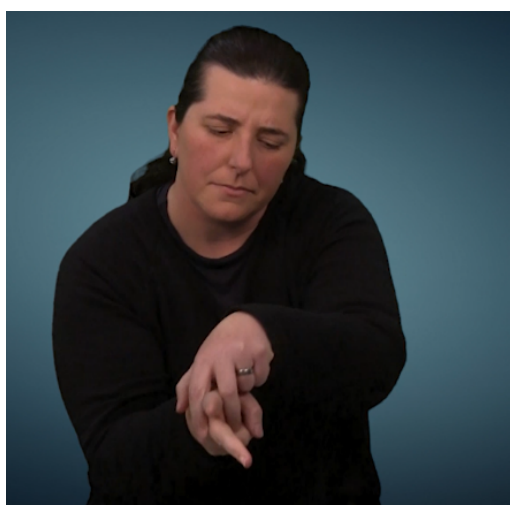

Fonte: Silva (2018, p. 165).

Nesta imagem, temos o exemplo da sinalizante demonstrando, por meio da CM esquerda, que uma pessoa está sentada (com as pernas encolhidas) em um meio de locomoção de duas rodas, exibido pela CM direita. 
Expressões policomponenciais em libras: estatuto e processo de ensino e aprendizagem... Marcelo Porto • Lídia da Silva

Ocorre, todavia, que realizações diferentes dessas estiveram largamente presentes nas sinalizações dos participantes do estudo de Silva (2018). Uma amostra é apresentada na Figura 9.

\section{Figura 9 - Variação na realização do sinal de ANDAR-DE-BICICLETA}

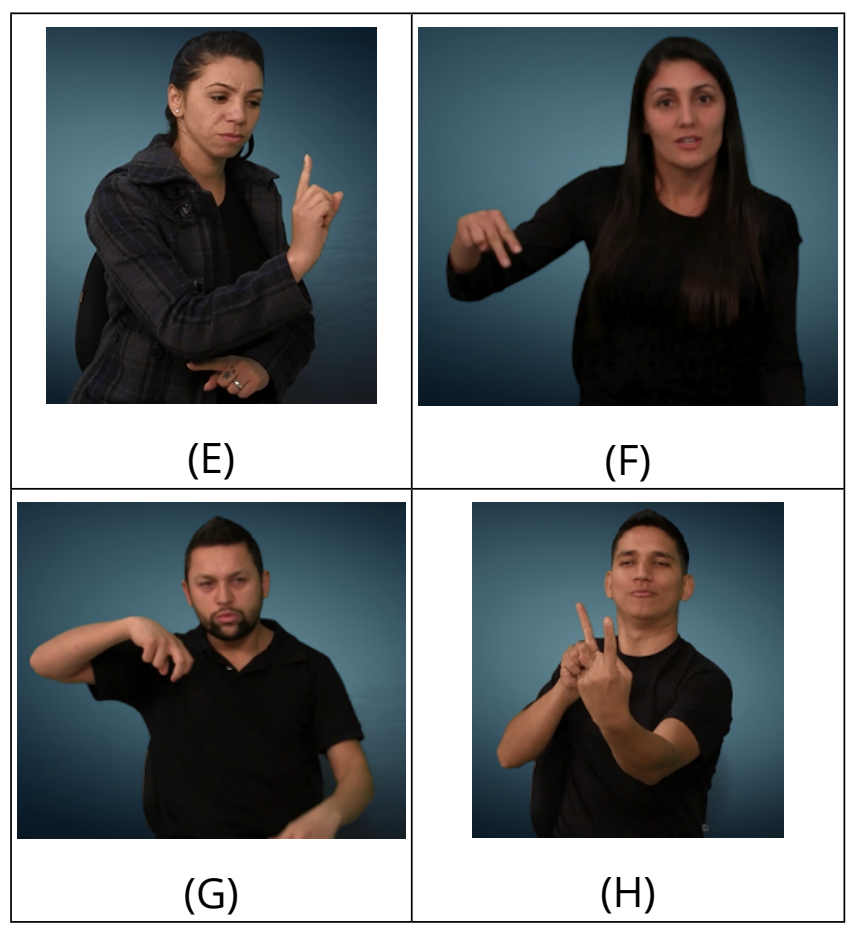

Fonte: Silva (2018, p. 166).

Segundo Silva (2018), os sinais das imagens apresentadas em (E) e $(H)$ parecem não dar conta de transmitir a ideia de ANDAR-DE-BICICLETA, pois eles se referem à incorporação de entidade pessoa em pé (a $\mathrm{H}$ alude a duas pessoas, no caso). A imagem em (F), segundo a autora, mostra a participante realizando o sinal ANDAR-DE-BICICLETA sem preservar a iconicidade do transporte de duas rodas, já que optou por uma CM que remonta a ideia de uma pessoa que desloca-se a pé. Em (G), há uma variação de $(F)$, pois o sinalizante encolheu os dedos ao mesmo tempo em que os movimentou, trazendo, desse modo, certo estranhamento ao sinal.

Essa análise parece confirmar a hipótese de que realizações de movimento e localização são realizadas corretamente, pois re- 
Expressões policomponenciais em libras: estatuto e processo de ensino e aprendizagem... Marcelo Porto • Lídia da Silva

ferem-se a traços gestuais pertencentes ao repertório dos sinalizantes, os quais foram transferidos a Libras (TAUB et al., 2008). Ao passo que, tal como diz Liddell (2003), a CM é a unidade lexical ampla e, por isso, precisa ser aprendida pelos ouvintes.

Fosse essa realização considerada inteiramente linguística - mesmo que intrínseca à gestualidade - como defendido por Frydrych (2019), como poderia se explicar que na produção sinalizada de ouvintes aprendizes de Libras como L2, alguns traços do verbo policomponencial ANDAR-DE-BICICLETA ocorrem corretamente enquanto outros não?

Ao que parece, os dados de Silva (2018) são evidências das ideias de Fuks e Tobin (2009) acerca de que os gestos desempenham um papel fundamental à produção em Libras - principalmente na formação das expressões policomponenciais - já que, dada sua modalidade visual, há facilidade de expressão de imagens, as quais podem influenciar e aprimorar processos associados à formação e uso dos elementos linguísticos. Todavia, é necessário que os ouvintes aprendizes desenvolvam, de alguma forma, esse pensamento imagético para melhorar tal produção.

Kurz, Mullaney e Occhino (2019), por meio de pesquisa longitudinal, investigaram 11 alunos ouvintes sinalizantes de ASL como L2. Na primeira coleta, os aprendizes estavam matriculados no nível básico 1 (T1) e, na segunda, - que se deu 6 meses depois - estavam cursando o básico 2 (T2). Em seção individual, os ouvintes assistiram ao desenho animado Piu-Piu e Frajola e depois o recontaram em ASL.

As autoras mostram, conforme ilustração da Figura 10, que na primeira seção uma das participantes fez uso de uma construção gestual para se referir à ação de PROCURAR (imagem I), enquanto que na segunda seção, substituiu a realização por um item lexical convencionalizado na língua (imagem J). 
Expressões policomponenciais em libras: estatuto e processo de ensino e aprendizagem... Marcelo Porto • Lídia da Silva

Figura 10 - Produção do verbo PROCURAR em ASL (versão 1 e versão 2)

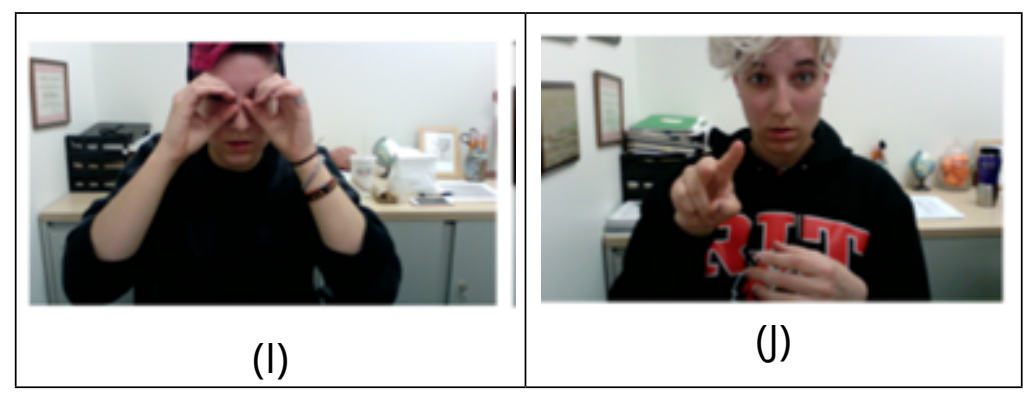

Fonte: Kurz, Mullaney e Occhino (2019, p. 10).

Casos como esses foram muito comuns nos dados analisados pelas autoras (8 ocorrências dentre as 11), o que leva a mais uma indagação: se o estatuto linguístico da gestualidade, segundo a perspectiva saussuriana apresentada por Frydrych (2019), se confirmasse, então, a materialidade gestual (corpo-em-ação) sempre presente nas línguas orais, não poderia ser mais facilmente transposta a uma L2 sinalizada? Segundo Kurz, Mullaney e Occhino (2019), a preferência de realização de sinais convencionalizados ao invés de gestos outrora usados é em decorrência do progresso no estudo e a exposição cada vez maior a vocabulários, o que leva os aprendizes a tentativas de sinalização que, segundo suas percepções, são mais parecidas com ASL.

No estudo de Taub et al. (2008, p. 281), os autores constatam essa mesma reflexão, pois dizem

observamos muitos de nossos sujeitos se esforçando para concentrar a atenção em itens do vocabulário na ASL. Isso pode ter inibido o uso espontâneo do discurso em primeira pessoa nas narrativas.

Presumivelmente, a inibição do uso dos gestos acaba por prejudicar a produção do aprendiz de L2 ao invés de favorecê-lo, isso porque os gestos têm papel crucial na estruturação de discursos sinalizados (LIDDELL, 2003). 
Expressões policomponenciais em libras: estatuto e processo de ensino e aprendizagem... Marcelo Porto • Lídia da Silva

Kurz, Mullaney e Occhino (2019) apontam ainda que houve muitas representações inadequadas para os verbos policomponenciais. Note-se o exemplo a seguir, extraído da primeira e da segunda seção de um mesmo participante.

Figura 11 - Produção do verbo PROCURAR em ASL (versão 1 e versão 2)

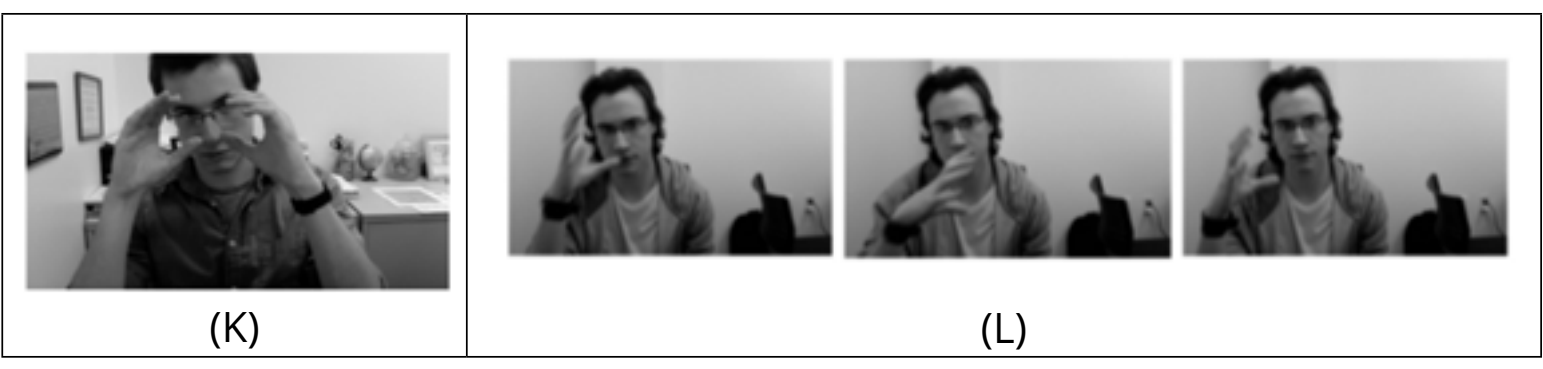

Fonte: Kurz, Mullaney e Occhino (2019, p. 11).

Tais construções foram consideradas malsucedidas uma vez que o olhar, a expressão e o movimento da cabeça e do corpo do sinalizante não se alinham com as características reais do referente. Isso porque, tanto em (K) quanto em (L), o sinalizante realizou o movimento com a mão no espaço à frente do corpo, mas o seu olhar, ao invés de acompanhar o movimento das mãos, permaneceu fixo na direção do interlocutor. Essa análise das autoras confirma o que Taub et al. (2008, p. 281) afirmam a respeito da transferência da gestualidade à ASL de que é "mais difícil se adquirir o uso linguístico do olhar no discurso do que se adquirir a expressão facial". Ao que parece, dizem as pesquisadoras, "o aluno está ciente, mas ainda não adquiriu completamente aos elementos formais apropriados desta construção" (KURZ, MULLANEY, OCCHINO, 2019, p 11).

Outrossim, Kurz, Mullaney e Occhino (2019) apontam que não se observa aumento geral no uso dessa estrutura ao longo do tempo, pelo contrário, muitos aprendizes demonstram diminuição do uso. Se essas realizações fossem "apenas" signos linguísticos, os alunos, se não já as tivessem aprendido, demonstrariam progresso no uso. Entretanto, os verbos policomponenciais parecem mes- 
Expressões policomponenciais em libras: estatuto e processo de ensino e aprendizagem... Marcelo Porto • Lídia da Silva

mo tratar-se de uma conceitualização realizada pelo corpo físico, que toma por base os estímulos sensoriais e o conhecimento de mundo (SILVA, 2014).

Com o exposto podemos, sinteticamente, trazer resposta à segunda pergunta de pesquisa, a saber: "o que podemos considerar a respeito do processo de ensino e aprendizagem das expressões policomponencias da Libras ao aprendiz de L2?":

a. alguns traços constituidores das expressões policomponencias são adquiridos mediante processo de transferência da gestualidade, qual seja: localização, direção e movimento;

b. a CM é o componente linguístico básico que precisa ser aprendido de modo que se possa realizar codificação de entidade e superfície de forma mais icônicas;

c. a aprendizagem de expressões policomponenciais relaciona-se ao desenvolvimento do pensamento imagético;

d. a aprendizagem de expressões policomponenciais aciona questões relativas aos processos de ensino e, por isso, faz-se necessário o incentivo de produções gestuais espontâneas em detrimento ao uso restrito de vocabulários convencionalizados na Libras;

e. há necessidade de instrução e treinamento a respeito do uso do olhar uma vez que, diferentemente do que ocorre com as expressões faciais, esse traço é de maior dificuldade de assimilação pelos aprendizes;

f. a aprendizagem de expressões policomponenciais necessita que os estímulos sensoriais, o conhecimento de mundo e as experiências linguísticas dos aprendizes sejam aproveitados ao longo do processo de ensino.

Por fim, é preciso destacar, ainda, que os pontos acima elencados referem-se a uma tentativa de organização do quadro teórico, haja vista que fazem menção a uma concepção de aprendizagem 
Expressões policomponenciais em libras: estatuto e processo de ensino e aprendizagem... Marcelo Porto • Lídia da Silva

de L2 que entende que aprender uma língua implica não apenas em adquirir a estrutura formal do sistema simbólico, mas também ativar processos cognitivos gerais e fazer uso da experiência corporal diária.

\section{Conclusão}

Este trabalho teve como objetivo discutir o estatuto das expressões policomponenciais da Libras e refletir sobre o processo de ensino e aprendizagem dessas expressões pelo aprendiz ouvinte brasileiro. Para cumprir esse objetivo, realizou-se análise crítica e interpretativista de literatura e de dados apresentados nas publicações de Taub et al. (2008), Silva (2018) e Kurz, Mullaney e Occhino (2019).

Na primeira seção, o texto baseou-se em Frydrych (2019) para apresentar a visão da linguística saussuriana e em Liddell e Metzger (1998), Liddel (2003) e McCleary e Viotti (2011) para apresentar os constructos da linguística cognitiva para o estatuto das expressões policomponenciais e, por questões de poder argumentativo, aderiu-se a essa última visão. Apesar disso, pensa-se que essas diferentes concepções têm em comum o fato de apontarem para a criatividade do falante que é revelada em Libras por meio do uso de elementos linguísticos e gestuais (quer seja de forma combinada ou intrínseca).

A respeito do processo de ensino e aprendizagem, apontamos na segunda seção deste artigo que os ouvintes fazem uso do movimento, da localização e da direção em gestos que ocorrem com a fala oral, e que esses gestos serão utilizados na aprendizagem de uma língua sinalizada. Com isso, acreditamos que se o professor incentivar o uso do repertório gestual dos alunos, quando eles aprenderem os componentes linguísticos, principalmente a CM, poderão fazer conceitualizações mais complexas no espaço token e demonstrar um pensamento imagético no uso de expressões policomponenciais. 
Expressões policomponenciais em libras: estatuto e processo de ensino e aprendizagem... Marcelo Porto • Lídia da Silva

Findadas as considerações, encerramos com a compreensão de que este estudo contribui para o avanço da discussão a respeito das expressões policomponenciais em Libras, bem como do seu processo de ensino e aprendizagem em L2. Na espera de que novos trabalhos surjam a partir desta iniciativa, concluímos com o desejo de provocar um pensamento diferente do que está posto.

\section{Referências}

ANCHIETA, Ester Vitória Basilio. Incorporação e partição do corpo: o espaço sub-rogado no discurso narrativo de uma tradução de literatura infantil do português para a libras. 2017. 190f. Dissertação (Mestrado em Estudos da Tradução) - Centro de Comunicação e Expressão Programa de Pós Graduação em Estudos da Tradução - Universidade Federal de Santa Catarina, Florianópolis, 2017.

BARBOSA, Thais Bolgueroni. Uma descrição do processo de referenciação em narrativas contadas em língua de sinais brasileira (libras). 2014. 155f. Dissertação (Mestrado em Linguística) - Faculdade de Filosofia, Letras e Ciências Humanas - Universidade de São Paulo, São Paulo, 2014.

BOERS-VISKER, Eveline.; VAN DEN BOGAERDE, Beppie. Learning to use space in the $L 2$ acquisition of a signed language: two case studies. Sign Language Studies, v. 19, n. 3, p. 410-452, 2019. Disponível em: https:// www.researchgate.net/publication/333391547_Learning_to_Use_ Space_in_the_L2_Acquisition_of_a_Signed_Language_Two_Case_Studies. Acesso em: 02 dez. 2020.

CARNEIRO, Bruno Gonçalves. Corpo e classificadores nas línguas de sinais. Revista Sinalizar, v. 1, n. 2, p. 118-129, 2016. Disponível em: https://www.revistas.ufg.br/revsinal/article/view/36863. Acesso em: 02 dez. 2020.

CORREA, Rosemeri Bernieri de Souza. A complementaridade entre língua e gestos nas narrativas de sujeitos surdos. 2007. $166 f$. 
Expressões policomponenciais em libras: estatuto e processo de ensino e aprendizagem... Marcelo Porto • Lídia da Silva

Dissertação (Mestrado em Linguística) - Centro de Comunicação e Expressão, Universidade Federal de Santa Catarina, 2007.

DUNCAN, Susan. Gesture in signing: a case study from Taiwan Sign Language. Language and linguistics taipei, v. 6, n. 2, p. 279, 2005. Disponível em: https://www.researchgate.net/publication/241088772_ Gesture_in_Signing_A_Case_Study_from_Taiwan_Sign_Language. Acesso em: 02 dez. 2020.

FUKS, Orit; TOBIN, I. The Semiotic Notion of Gesture in Israeli Sign Language. In: GESPIN 2019 -GESTURE AND SPEECH IN INTERACTION, 1 Edição, 2009, Paderborn, Proceedings of GESPIN, 2019 p (1-6). Disponível em: https://www.researchgate.net/publication/332036200_ The_semiotic_notion_of_gesture_in_Israeli_Sign_Language. Acesso em: 02 dez. 2020.

FRYDRYCH, Laura Amaral Kümmel. Gestualidade nas línguas de sinais à luz do princípio saussuriano da dupla essência da linguagem. Cadernos do IL, v. 1, n. 59, p. 169-184, 2019. Disponível em: https://seer.ufrgs.br/ cadernosdoil/article/view/93324. Acesso em: 02 dez. 2020.

KENDON, Adam. Gesture: visible action as utterance. Cambridge: Cambridge University Press, 2004.

KURZ, Kim B.; MULLANEY, Kellie; OCCHINO, Corrine. Constructed action in American Sign Language: a look at second language learners in a second modality. Languages, v. 4, n. 4, p. 90, 2019. Disponível em: https:// www.mdpi.com/2226-471X/4/4/90. Acesso em: 02 dez. 2020.

LEITE, Tarcisio de Arantes. A segmentação da língua de sinais brasileira (libras): Um estudo lingüístico descritivo a partir da conversação espontânea entre surdos. 2008. 280f. Tese (Doutorado em Letras). Faculdade de Filosofia, Letras e Ciências Humanas, Universidade de São Paulo, São Paulo. 2008.

LIDDELL, Scott. K. Real, surrogate, and token space: grammatical consequences in ASL. In: EMMOREY, K; REILLY, J. (Org). Languages, gesture and space. Hillsdale: Lawrence Erslbaum Associates, p. 19-41, 1995. LIDDELL, Scott K; METZGER, Melanie. Gesture in sign language discourse. Journal of pragmatics. v. 30, n. 6, p. 657-697, 1998. 
Expressões policomponenciais em libras: estatuto e processo de ensino e aprendizagem... Marcelo Porto • Lídia da Silva

Disponível em: https://www.sciencedirect.com/science/article/abs/pii/ S0378216698000617. Acesso em: 02 dez. 2020.

LIDDELL, Scott K. Grammar, gesture, and meaning in American Sign Language. Washington: Cambridge University Press, 2003.

MCCLEARY, Leland; VIOTTI, Evani. Língua e gesto em línguas sinalizadas. Revista Veredas, v. 15, n. 1, 2011. Disponível em: https://www.ufjf.br/ revistaveredas/files/2011/05/ARTIGO-212.pdf. Acesso em: 02 dez. 2020.

MCNEILL, David. Catchments and contextos: non-modular factors in speech and gesture production. In MCNEILL, D. (org). Language and Gesture, Cambridge: Cambridge University Press 2000, p. 312-328, 2000. MOREIRA, Renata Lúcia. Uma descrição de Dêixis de Pessoa na língua de sinais brasileira: pronomes pessoais e verbos indicadores. 2007. 150f. Dissertação (Mestrado em Linguística) - Faculdade de Filosofia, Letras e Ciências Humanas, Universidade de São Paulo, São Paulo, 2007.

PORTO, Marcelo. Transferências Visuais: um recurso indispensável na comunicação da Libras. 2016. 91f. Dissertação (Mestrado em Linguística) - Centro de Comunicação e Expressão, UFSC - Universidade Federal de Santa Catarina, Florianópolis, 2016

SILVA, Lídia; STRAZZI, Thayse Goulart. Marcadores discursivos em libras. Revista Sinalizar, v. 2, n. 2, p. 198-217, 2017. Disponível em: https:// www.revistas.ufg.br/revsinal/article/view/47260. Acesso em: 02 dez. 2020.

SILVA, João Paulo da. Demonstrações em uma narrativa sinalizada em libras. 2014. 151f. Dissertação (Mestrado em Linguística) Faculdade de Filosofia, Letras e Ciências Humanas, Universidade de São Paulo, São Paulo, 2014.

SILVA, Lídia da. Fluência de ouvintes sinalizantes de Libras como segunda língua: foco nos elementos da espacialização. 2018. 223f. Tese (Doutorado em Linguística) -Universidade Federal de Santa Catarina, Florianópolis, 2018.

TAUB, Sarah et al. Gesticulação e aquisição da ASL como segunda língua. In: QUADROS, Ronice Müller de; VASCONCELLOS, Maria Lúcia Barbosa de. Questões teóricas das pesquisas em língua de sinais. Petrópolis, RJ: Editora Arara Azul, 2008. p. 275-285. 
Expressões policomponenciais em libras: estatuto e processo de ensino e aprendizagem... Marcelo Porto • Lídia da Silva

WILCOX, Sherman. Routes from gesture to language. Revista da abralin, v. 4, n. 1 e 2, p. 11-45, 2005. Disponível em: https://revistas.ufpr.br/ abralin/article/view/52651. Acesso em: 02 dez. 2020. 